\title{
UAB
}

Universitat Autònoma

de Barcelona

This is the accepted version of the article:

Solé Ferré, Jordi; Brummund, Jan (InnoSyn B.V.); Caminal i Saperas, Glòria; [et al.]. «Ketoisophorone synthesis with an immobilized alcohol dehydrogenase». CHEMCACHEM, Vol. 11, issue 19 (Oct. 2019), p. 4862-4870. DOI $10.1002 /$ cctc. 201901090

This version is avaible at https://ddd.uab.cat/record/214989

under the terms of the C ${ }_{\text {COPYRIGHT license }}^{\mathbb{N}}$ 


\section{Keto-isophorone synthesis with an Immobilized Alcohol Dehydrogenase}

Jordi Solé[a], Jan Brummund[b], Glòria Caminal[c], Martin Schürman[b], Gregorio Álvaro[a] and Marina Guillén*[a].

Abstract: The monoterpenoid $\alpha$-isophorone is sourced from the available and renewable plant dry matter, as well as a waste recovery operation from acetone. This compound, can be hydroxylated to 4-hydroxy-isophorone which is the main precursor for the synthesis of keto-isophorone. On its turn, keto-isophorone is a key intermediate for the production of carotenoids and Vitamin E.

Here, the enzymatic oxidation of 4-hydroxy-isophorone to ketoisophorone is demonstrated employing an alcohol dehydrogenase (ADHaa) from Artemisia annua and a NADPH oxidase (NOX), as a cofactor regeneration enzyme. After 24h of reaction and an initial substrate concentration of $50 \mathrm{mM}, 95.7 \%$ yield and a space time yield of 6.52 g L $^{-1}$ day $^{-1}$ could be obtained.

Furthermore, the immobilization of the alcohol dehydrogenase was studied on 17 different supports. An epoxy-functionalized agarose resulted in the highest metrics, 100 $\pm 0 \%$ immobilization yield and $58.2 \pm 3.5 \%$ retained activity.

Finally, the immobilized ADHaa was successfully implemented in 4 reaction cycles (96h operation) presenting a biocatalyst yield of $23.4 \mathrm{~g}$ product g-1 of enzyme. It represents a 2.5 -fold increase compared with the reaction with soluble enzymes.

\section{Introduction}

The combination of environmental consciousness and legislation is paving the way towards a steeply increasing bio-based economy. However, the petro-alternative still remains as the major carbon source worldwide[1]. To revert this, the scientific knowledge is playing an important role, offering a continuously updated portfolio of highly competitive processes and products.As a result, the industry and in turn, the society, is becoming more sustainable and eco-friendly[2].

One of the most prominent and highly energetic resources on earth, apart from petroleum, is lignocellulose. Defined as "plant dry matter", this raw material is accessible, renewable, recyclable and vastly abundant. All sorts of products such as polysaccharides,lignin, oils, fragrances, phenolic compounds or building block chemicals can be obtained from lignocellulose[3,4].

Among them, $\alpha$-isophorone (3,5,5-Trimethyl-2-cyclohexen-1-one)(ISO) is a monoterpenoid that can be converted into intermediates for the production of polyurethans[5], pharmaceuticals[6], fragrances[7], etc. The chemical route towards some of these compounds comprises the isomerization of $\alpha$-isophorone to $\beta$-isophorone and the further oxidation of this, to keto-isophorone(KET)[8]. However, the first step (isomerization) requires the use of high temperatures and the equilibrium is shifted towards the substrate, only $2 \%$ yield is commonly obtained[9]. The direct selective allylic oxidation of ISO to KET has also been demonstrated, nevertheless, it makes use of toxic heavy metals, yields undesired by-products and/or requires harsh conditions[10-

12]. Apart from its biomass origin, $\alpha$-isophorone is also produced at large scale as a waste recovery operation from industry. An aldol condensation is run using potassium hydroxide and the acetone obtained as by-product from the synthesis of phenol[13]. 
Once the KET has been synthesized, it can then be reduced to (4R,6R)-actinol which is an intermediate for the production of zeaxanthin, cryptoxanthin and xanthoxin[14]. Furthermore, keto-isophorone can also be converted to trimethylhydroquinone, a key intermediate for the synthesis of $\alpha$-tocopherol (vitamin E)[15].

A greener and more sustainable strategy to obtain KET is the enzyme catalyzed hydroxylation of $\alpha$-isophorone to 4-hydroxyisophorone (HID) and the further oxidation of this to obtain the desired product (KET). Tavanti et al. co-expressed a selfsufficient P450 together with an alcohol dehydrogenase from Candida magnoliae to run the reaction as one-pot two step oxidation and obtained a space-time yield of $1.4 \mathrm{~g} \mathrm{~L}^{-1}$ day ${ }^{1}[16]$. In

this same line, Shaghayegh et al. compared the performance of two P450 (CYP102A1 and CYP101A1) for the hydroxylation of ISO, however, background activity from the E. coli host cells converted the recently formed KET to levodione[17]. Another recent example is from Aranda et al. that used an unspecific peroxygenase from Humicola insolens to fully convert $10 \mathrm{mM}$ ISO in a 1:1 ratio (HIP:KET)[18].

As previously reported by Kaluza et al., the first oxidation step,the hydroxylation of ISO to 4-hydroxy-isophorone is feasible and it was demonstrated at pilot plant scale[19,20]. The biocatalyst utilized consisted of E. coli whole cells over-expressing a P450 BM3 and a Glucose dehydrogenase, that served as the cofactor regeneration enzyme. The $100 \mathrm{~L}$ reactions performed, resulted in $80-82 \%$ conversion of the initial $6.3 \mathrm{~mol}$ of ISO, with a spacetime yield of $1 \mathrm{~g} \mathrm{~L}^{-1} \mathrm{~h}^{-1}$. The present work has been focused on the subsequent oxidation step, the conversion of HID to KET.

In order to study the enzyme-mediated oxidation of HID, an alcohol dehydrogenase from Artemisia annua (ADHaa) (EC1.1.1.1) was selected out of 5 different candidates (data not shown). Furthermore, immobilization of ADHaa on differentsupports was investigated in order to re-use the enzyme in various cycles of reaction. In this sense, immobilization often results in an increased stability of the catalyst and allows an ease separation of the enzymes from the reactor content[21-23].

Numerous are the examples in literature about immobilized alcohol dehydrogenases[24-27], however, this is the first time that immobilization has been studied on Artemisia annua's ADH.

Regarding the NADPH, since the cofactor dependence is a drawback that hampers the use of alcohol dehydrogenases at large scale, an NADH oxidase from Streptococcus mutans (NOX) (EC 1.6.3.4) engineered to accept NADPH, was used as a cofactor regeneration enzyme (Figure 1)[28-30]. The immobilization of NOX is not presented here due to the fact that previous results obtained with this enzyme, did not show any significant operational improvement (data not shown).

Figure 1.

\section{Results and Discussion}

Characterization of the cell lysates

Prior to any immobilization or operational study, the cell lysates with over-expressed ADHaa and NOX were characterized accounting for total protein content, target enzyme content (Supporting information, Figure S1) and activity.

Table 1.

The obtained results are shown in Table 1. As it can be observed,ADHaa lysate contained lower amounts of protein and the enzyme was present in a lower ratio to the E. coli background proteins, compared with the NOX extract. In terms of specific 
activity, ADHaa was 5.1-fold less active than the cofactor regeneration enzyme, towards the substrates and conditions of these activity tests. Aiming to select the most suitable strategies for ADHaa immobilization, its stability at different $\mathrm{pH}$ values $(6,7,8$ and 9) was assessed. It is known that the activity decay of the enzyme at certain $\mathrm{pH}$, partially determines the immobilization method to be used[31]. As it can be seen in Figure 2, ADHaa maintained more than $80 \%$ of the initial activity after 2 hours at $\mathrm{pH} 7,8$ and 9 . Under pH 6 ADHaa showed to be less stable, reaching 30\% of the initial activity after 1 hour. Theoretically, alkaline media are more suitable for epoxy and/or aldehyde functionalized supports and, on the other hand, $\mathrm{pH} 6$ is more appropriate for

Figure 2.

amino functionalized carriers[32]. Anyhow, a screening set of supports presenting different features and all three functionalizations was studied.

Table 2,

Table 3.

Immobilization of ADHaa onto methacrylate/styrene supports

As explained in the introduction, immobilization can confer added benefits to industrial biocatalysts. By improving stability or allowing its re-cycling, an immobilized biocatalyst can reduce the overall cost of the process. In this sense, commercial carriers as the ones used in this study, are a good primary choice due to the ease of large-scale supply.

A commercial screening set of methacrylate/styrene materials presenting different features was studied. The carriers had different pore diameters (300 - $1800 \AA$ ), enzymecarrier interactions (ionic, covalent and hydrophobic), functional groups (epoxy, amino and aldehyde), linker lengths (C2 - C18), material matrices (methacrylate and/or

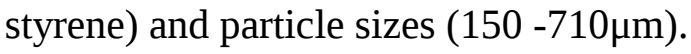

Only those supports presenting at least $40 \%$ immobilization yield (IY) and 20\% retained activity (RA) are presented in Table 2. All the other trials are presented in Table S1 (Supporting information). As it can be seen (Table 2), two carriers fulfilled this criteria: an epoxy-functionalized (ECR8215F) and an amino-functionalized (ECR8409F) methacrylate. In both cases, even though the immobilization yield (IY) almost reached $100 \%$, the retained activity was low $(\approx 20 \%)$.

In the immobilization on the epoxy-functionalized methacrylate (ECR8215F), the ADHaa showed good affinity for the support. All the offered activity was attached to the resin after $0.5 \mathrm{~h}$ incubation $(99.9 \pm 0.1 \%$ IY). The final RA and IY values were obtained after

2 hours incubation. In the case of the amino-functionalized methacrylate (ECR8409F), the immobilization occurs in diferent

The ionic adsorption of the enzyme to the carrier (0.5h), which is the first step, resulted in $98.3 \pm 0.1 \%$ immobilization yield and $24.2 \pm 5.2 \%$ retained activity. However, being 7.2 the optimum $\mathrm{pH}$ for the target reaction, this method was not considered adequate. When $10 \mathrm{mM} \mathrm{N}$-(3-dimethylaminopropyl)-N'-ethylcarbodiimide (EDC) was added to promote the covalent binding, the retained activity was reduced to $20.2 \pm 2.1 \%$ (2.5h). In all cases, certain activity loss (5 to 10\%) corresponds to the intrinstic deactivation of ADHaa over time in the immobilization conditions (Figure 2). 
The functionalization of the carrier turned out to be not excluding, since each support presented a different functional group (epoxy or amino). Before trying to optimize the immobilization of the ADHaa on the methacrylate-based supports presented so far (ECR8215F an ECR8409F), a more hydrophilic matrix harboring the same functional groups (epoxy and amino) was also tested.

Immobilization of ADHaa onto epoxy and aminofunctionalized agaroses

The common feature that all methacrylate/styrene materials share

is the higher hydrophobicity and rigidity that they present compared with, for instance, a hydrogel such as agarose[32-34]. Therefore, as already mentioned, an agarose matrix was

considered to be tested aiming to study if higher retained activities could be achieved. Three agaroses were tested: an aminofunctionalized (Mana) and two epoxyfunctionalized with diferent activation grades: M1 $\left(30 \pm 3 \mu \mathrm{mol} \mathrm{g}{ }^{-1}\right)$ and M2 (106 \pm 1 $\mu \mathrm{mol} \mathrm{g} \mathrm{g}^{-1}$.

The results are presented in Table 3. Regarding Mana-agarose,three $\mathrm{pH}$ values were tested (6, 6.5 and 7). It can be seen that the immobilization yield was very low (14.3 \pm $3.3 \%$ ) when the immobilization was performed at $\mathrm{pH}$ 7. This result could be related to the $\mathrm{pKa}$ of the primary amine of Mana-agarose. When the $\mathrm{pH}$ is higher than the $\mathrm{pKa}$ (6.8) the amino-groups are deprotonated and, therefore, the first step of the immobilization, i.e. the iònic adsorption of the enzyme towards the support, is not favored. On the other hand, when the immobilization with Mana-agarose was pursued at $\mathrm{pH} 6.0$ or 6.5, even though the immobilization yields were higher than the $\mathrm{pH} 7$ case, the final retained activities were

lower due to the high instability of ADHaa at $\mathrm{pH}<7$. Regarding the Epoxy-agaroses, when the immobilization occurs at $\mathrm{pH}$ close to 10, it favors the epoxy-ring opening and so the covalent bond formation with the amino groups of the enzyme [33]. The first studies were carried out with Epoxy-agarose M1 by testing two $\mathrm{pH}$ values, 8 and 9. In this line, $\mathrm{pH} 9$ (Figure $3 \mathrm{~A}$ ) significantly improved the results by increasing the immobilization yield 2.3-fold, compared to $\mathrm{pH}$ 8. Therefore, $\mathrm{pH} 9$ was selected to test the

Epoxy-agarose M2 which presents a 3.5-fold higher activation grade compared with M1. The utilization of Epoxy-agarose M2 (Table 3), resulted in 1.6-fold higher retained activity compared with the less activated Epoxy-agarose M1. As it can be seen in Figures $3 \mathrm{~A}$ and $\mathrm{B}$, the suspension activity profile is similar in both cases, a gradual drop of the suspension activity over time. The reason behind this behavior can be the progressive multi-point attachment of the enzyme to the support[35]. The epoxy groups of the carrier initially react with the amino groups of the enzyme creating a first binding. Over time though, the epoxy groups start reacting with the carboxyl and thiol groups of the enzyme

generating a second multipoint binding that can partially deactivate the ADHaa. Comparing the two figures, in the second case, the decrease is less pronounced and it levels off after 3 hours of incubation. This different behavior could be attributed to the enzyme's nature and its specific interaction with the differently distributed epoxy groups. When using other enzymes such as the cytochrome P450 BM3 (CYP102A1), the opposite effect has been reported[36]. Is the first time that an alcohol dehydrogenase from Artemisia annua has been successfully immobilized. 
Immobilization of ADHaa on Epoxy-agarose M1 and M2 applying high loads of enzyme

The immobilizations presented in Table 2, 3 and Figure 3 werecarried out loading the supports with low amounts of enzyme, minimizing the possible diffusional limitations. Thus, it allows the characterization of the immobilization processes. However, in order to ideally study an immobilized biocatalyst in an industrial target reaction, the support should contain the highest number of units of activity possible[21]. To do so, the two best performing carriers, according to the IY and RA obtained during characterization, were chosen: Epoxy-agarose M1 and Epoxyagarose M2 (pH 9).

In Figure $3 \mathrm{~A}$ and $\mathrm{B}$, as aforementioned, it can be observed that the suspension activity slightly decreases over time, especially in Figure $3 \mathrm{~A}$, reducing like this the retained activity and also the multiplying factor (Table 4). At the same time, the longer the immobilization time, the higher is the amount of enzyme that can be attached to the support (Attached units). Therefore, in order togenerate an immobilized derivate with the highest activity possible (Specific activity), a compromise must be found between the amount of units attached to the support (longer immobilization times) and the multiplying factor (shorter immobilization times).

As it can be observed in Table 4, the optimum immobilization time for Epoxy-agarose M1 was 3 hours leading to $119.9 \mathrm{U} \mathrm{g}^{-1}$ of support, and for Epoxy-agarose M2 it was 4 hours with $195.7 \mathrm{U} \mathrm{g}^{-1}$ of support. This second immobilization leaves room for improvement since longer immobilization times could result in higher specific activities. Anyhow, Epoxy-agarose M2 (pH 9 and 4h) was chosen as the best carrier to be studied in the target reaction.

Oxidation of 4-hydroxy-isophorone to keto-isophorone: soluble and immobilized biocatalysts

The target reaction was primary studied using both the ADHaa and NOX in its soluble form, as cell free extracts. The results obtained can be seen in Figure 4 A. As the graph shows, the reaction time was set at 24 hours and the ADHaa load was adjusted so that at least $90 \%$ conversion was reached [ $5 \%$ ADHaa lysate $(\mathrm{v} / \mathrm{v})]$. The cofactor regeneration enzyme (NOX), as well as the oxygen supply, were assured to be non-limiting.

As the Figure 4 A shows, the final conversion was $92.2 \%$ and the yield was $95.7 \%$ indicating a slight mass balance gap of 3.5\%. Even though the oxygen gas was hydrated prior to be introduced in the reactor, certain evaporation could have occurred. Thus, a slight reduction of the reaction volume could increase both substrate and product concentration, causing the mass imbalance. The final metrics of the reaction can be seen on Table 5. The space time yield obtained after $24 \mathrm{~h}$ of reaction was $6.52 \mathrm{~g} \mathrm{~L}^{-1}$ day $^{-1}$.

Once the soluble reaction was performed, the ADHaa was immobilized on Epoxyagarose M2 in order to be applied in the target reaction. Regarding NOX, at the beginning of each cycle, it was added freshly as cell free extract.

The results regarding the re-utilization of the immobilized ADHaa are shown in Figure $4 \mathrm{~B}$ and $\mathrm{C}$. In the first case (Figure $4 \mathrm{~B}$ ), magnetic stirring was employed, causing an observable grinding of the agarose particles. This caused an obturation of the porous plate during filtration. In order to solve this issue, in the second case (Figure $4 \mathrm{C}$ ), mechanic stirring was used allowing a ràpid and efficient filtration every cycle. In this case no particle breakdown was observed. As it can be seen, when the ADHaa was 
immobilized, the biocatalyst could be re-used up to 4 times. However, the conversion decreased from cycle to cycle in Figure 4 B: 1) 95.4\% conversion and 85.6\% yield, 2) 83.8\% conversion and $76.4 \%$ yield,

3) $46.6 \%$ conversion and $46.4 \%$ yield and 4) $14.1 \%$ conversion and $15.8 \%$ yield; and also in Figure 4 C: $90.4 \%$ conversion and $82.1 \%$ yield, 2) $81.7 \%$ conversion and $76.8 \%$ yield, 3) 67.9\% conversion and 59.8\% yield and 4) $36.0 \%$ conversion and 35.1\% yield. The mass balance varied from 87.0 to $101.7 \%$ in both cases. In Table 5 a final summary of the reaction metrics can be found. When immobilized ADHaa was used, the biocatalyst yield (g KETg-1 enzyme) obtained for this enzyme was improved compared with the soluble enzyme. The reactions performed under magnetic stirring and mechanical stirring led to similar biocatalyst yields (23.4 $\mathrm{g} \mathrm{KET} \mathrm{g}^{-1}$ enzyme and $20.2 \mathrm{~g}$ KET $\mathrm{g}^{-1}$ enzyme) representing among 2.5 and 2.1-fold improvement, respectively. Regarding NOX, it should be taken into account that, while ADHaa is used immobilized and recycled, NOX is added freshly in each reaction cycle. That is why, the biocatalyst yield of NOX is lower when it is compared to that in the reaction with soluble ADHaa.

\section{Conclusions}

The enzymatic production of chemical compounds offers a greener alternative to the traditional routes in which often harsh conditions and reagents or expensive catalysts are employed [37].

When the synthesizedn compound is meant for nutritional purposes, biocatalysis also adds the possibility to include the "natural" label to the final product[38]. In this sense, the enzymatic oxidation of 4-hydroxy-isophorone would be a step forward towards more sustainable reaction routes. The product obtained, keto-isophorone, is a key intermediate for the synthesis of carotenoids and Vitamin E, among others. The synthesis of keto-isophorone catalyzed by an alcohol dehydrogenase has proven successful. Moreover, in order to avoid the addition of stoichiometric amounts of $\mathrm{NADP}+$, a NADPH oxidase was added as a cofactor regeneration enzyme. In $24 \mathrm{~h}$, up to 95.7\% of the initial $50 \mathrm{mM}$ substrate concentration could be converted into the desired product. The reaction showed a space time yield of $6.52 \mathrm{~g} \mathrm{~L}^{-1}$ day $^{-1}$ and good mass balances (96.5\%).

Immobilization of ADHaa was also studied as a strategy to improve the final metrics of the reaction. For the first time, an alcohol dehydrogenase from Artemisia annua could be

successfully immobilized on four different supports showing immobilization yields above $40 \%$ and retained activities above $20 \%$. In this sense, an epoxy-agarose excelled among the four showing $100 \pm 0 \%$ immobilization yield and $58.2 \pm 3.5 \%$ retained activity. Regarding the immobilization of NOX, it could be considered as an option to improve the process metrics. However, even though previous results of the research group were

successful on immobilizing NOX, the derivatives did not lead to an improved stability. The immobilized ADHaa was used in 4 consecutive reaction cycles, that lasted $24 \mathrm{~h}$ each. Two sets of 4 reaction cycles were performed comparing magnetic and mechanical stirring. As expected, the magnetic stirring significantly grinded the agarose particles and hampered the filtration. However, the breakdown of the particles did not entail a significant loss of activity when compared with the reaction mechanically stirred. At the end, the re-utilization of ADHaa implied from 2.1 to 2.5-fold increase in biocatalyst yield (20.2 to $23.4 \mathrm{~g} \mathrm{KET} \mathrm{g}^{-1}$ enzyme). 
These promising results on the use of immobilized enzymes open new possibilities to implement novel reactor configurations (e.g.plug flow design) that would allow, for example, the operation in continuous mode. By doing this, the filtration step could be avoided and/or the reactor could be loaded with more than $10 \%(\mathrm{w} / \mathrm{v})$ of support. Moreover, working with immobilized enzymes facilitate the product purification and allow the re-utilization of the enzyme. As a next step, an economic evaluation of the whole process, including the hydroxylation of $\alpha$-isophorone, should be performed in order to consider scaling up. Even though the immobilization of ADHaa and its implementation resulted successful, the added costs of the process could be detrimental to the final. Proper

process design of both reactions should pave the way for optimal pre-industrial preparation.

\section{Experimental Section}

Chemicals and suports

Nicotinamide adenine dinucleotide phosphate sodium salts in its oxidized and reduced form (NADP+ disodium salt and NADPH tetrasodium salt) were purchased from BONTAC Bioengineering (Shenzhen, China). 4-hydroxy-isophorone (> 98\%) was enzymatically produced and further purified following the work described by Kaluzna et al.[20]. The product reference Standard 2,6,6-Trimethyl-2-cyclohexene-1,4-dione (KET) (98\%) was bough from Sigma Aldrich (Ref. 329517-25G, St. Louis, USA). All the

other reagents were of analytical grade and purchased from Sigma-Aldrich if not stated otherwise. Buffer like solutions were prepared in advance and stored at $4-6^{\circ} \mathrm{C}$ for at most, three weeks.

Methacrylate/styrene resins were kindly donated by Purolite ${ }^{\circledR}$ Life Science (Bala Cynwyd, USA) and stored at $4-6^{\circ} \mathrm{C}$. A detailed description of the matrices can be found in Supporting information, Table S1. High density aminoethyl 4 BCL agarose (Manaagarose) as well as the non-functionalized agarose 4 BCL were purchased from Agarose Bead Technologies ${ }^{\circledR}$ (Madrid, Spain).

They presented a spherical shape, $50-150 \mu \mathrm{m}$ of particle diameter and, in the first case (Mana), presented and extent of labelling of $40-60 \mu \mathrm{mol} m L-1$. Epoxy-agarose method 1 (M1) was produced using the non-functionalized agarose 4 BCL and following the protocol described by Axarli et al.[39]. The Epoxyagarose method 2 (M2) was produced using the same matrix as the M1 but following the protocol described by Sundberg et al. [40].

The activation grade presented by the Epoxy-agaroses (M1 and M2) was accounted following the protocol described by Gupta[41].

Recombinant production of ADHaa and NOX

ADHaa from Artemisia annua and the NAD(P)H oxidase (NOX) variant from Streptococcus mutans were recombinantly produced in Escherichia coli in $10 \mathrm{~L}$ scale fed-batch, high cell-density fermentations with glucose as growth limiting carbon source employing an E. coli K12 derivative and a pBR322 derived expression vectors. $500 \mathrm{ml}$ pre-cultures were used to inoculate $10 \mathrm{~kg}$ main culture medium with $100 \mu \mathrm{g} \mathrm{mL}-$ ${ }^{1}$ neomycin. The precultures were prepared in standard Lysogeny broth (LB) mèdium supplemented with $5 \mathrm{~g} \mathrm{~L}^{-1}$ glycerol and $50 \mu \mathrm{g} \mathrm{mL} \mathrm{me}^{-1}$ neomycin. The fermentations were 
performed using mineral mèdium supplemented with $20 \mathrm{~g} \mathrm{~L}-1$ yeast extract ( $25 \mathrm{~g} \mathrm{~L}-1$ for NOX). Approximately $29 \mathrm{~h}$ after inoculation ( $25 \mathrm{~h}$ for NOX) of the fermenters as inducer, pre-sterilized L-rhamnose was added tothe fermenters to final concentrations of $0.5 \%\left(\mathrm{w} \mathrm{w}^{-1}\right)$. After about 102 and $126 \mathrm{~h}$ for ADHaa and NOX, respectively, the biomass (280 and $211 \mathrm{~g}$ cell wet weight per kg ADHaa and NOX fermentation broth, respectively) was harvested by centrifugation. Harvested cells were frozen at $-20^{\circ} \mathrm{C}$ and resuspended in twice their weight of $100 \mathrm{mM}$ potassium phosphate buffer $\mathrm{pH} 7.5$ and disrupted by homogenization using a Microfluidics M-110P homogenizer and stored at $-20^{\circ} \mathrm{C}$ until further use.

\section{Protein and enzyme concentration}

The protein content present in the cell free extracts containing the over-expressed ADHaa and NOX was measured by means of the Bradford Protein Assay Kit (Thermo Fisher Scientific, Waltham, USA), using bovine serum albumin as standard (0.05 - 0.5 $\left.\mathrm{mg} \mathrm{mL} \mathrm{m}^{-1}\right)$ [42].

The enzyme content was analyzed by means of the sodium dodecyl sulphate polyacrylamide gel electrophoresis (SDSPAGE) (NuPage 12\%, Invitrogen, USA) run in a Mini-PROTEAN II apparatus (BioRad, USA) following the protocol of Laemmli et al. [43]. Low range protein markers were used for the molecular weight determination. Gels were stained using Coomassie G250 colloidal stain solution [34\% (v/v) ethanol, $2 \%(\mathrm{v} / \mathrm{v}) \mathrm{H3PO} 4,17 \%(\mathrm{w} / \mathrm{v}) \mathrm{NH} 4 \mathrm{SO} 4$ and $0.066 \%$ Coomassie G250] and the Image LABTM software (BioRad, USA) was used for image processing. The images of the obtained gels are presented in Supporting information, Figure S1.

\section{Activity measurements}

The dehydrogenase (ADHaa) and oxidase (NOX) activity presented by the lysates was measured spectrophotometrically $(\lambda=340 \mathrm{~nm})$ following the consumption rate of NADPH ( $\left(\varepsilon=6.22 \mathrm{mM}^{-1} \mathrm{~cm}^{-1}\right)$. One unit of activity (U) is defined as the enzyme required to convert $1 \mu \mathrm{mol}$ of NADPH per minute at the given conditions. In both cases, $1 \mathrm{~mL}$ plastic micro cuvettes BRAND ${ }^{\circledR}$ UV (Sigma Aldrich ${ }^{\circledR}$ ) were used for the soluble enzymes and $3.5 \mathrm{~mL}$ quartz cuvettes HELLMA® 100-QS (Hellma Analytics, Mülheim, Germany) with magnetic stirring were used for the immobilized derivates. In the second case, with $3.5 \mathrm{~mL}$ cuvettes, the test amounts are 4-fold increased with respect to the soluble enzymes. The temperature was controlled and set at $30^{\circ} \mathrm{C}$. The absorbance was recorded using a spectrophotometer Cary 50 Bio UV-visible (Palo Alto, USA).

The ADHaa activity test was performed mixing $350 \mu \mathrm{L}$ of cyclohexanone (14.5 mM) dissolved in Sodium phosphate buffer (NaPi, $50 \mathrm{mM}, \mathrm{pH}$ 7), $125 \mu \mathrm{L}$ of NADPH (1 mM) dissolved in NaPi as well and $25 \mu \mathrm{L}$ of pre-diluted enzyme sample. The background consumption of NADPH by non-ADHaa E. coli enzymes present in the cell lysate was measured with the same test but omitting the addition of cyclohexanone. The background activity was subtracted from the ADHaa measured activity.

The NOX activity test was run mixing $300 \mu \mathrm{L}$ of NaPi buffer (50 mM, pH 6), $175 \mu$ of NADPH $(1 \mathrm{mM})$ dissolved in NaPi buffer $(50 \mathrm{mM}, \mathrm{pH}$ 6) and $25 \mu \mathrm{L}$ of pre-diluted enzyme sample. The background consumption of NADPH by non-NOX E. coli enzymes

present in the lysate was measured by bubbling nitrogen gas into the cuvette $(2-4$ min.) and so, stripping off the dissolved oxygen. The background activity of the lysate was subtracted from the NOX activity. In both cases the linear range was found between 
0.2 and $5 \mathrm{U} \mathrm{mL}^{-1}$ and the background activity never exceeded $5 \%$ of the total activity measured.

\section{ADHaa stability at different $\mathrm{pH}$ vàlues}

The activity decay of ADHaa was studied at different pH values: 6, 7, 8 and 9 (NaPi, 50 $\mathrm{mM}$ ). The $\mathrm{pH}$ was adjusted using either $1 \mathrm{M} \mathrm{NaOH}$ or $1 \mathrm{M} \mathrm{HCl}$. The initial activity of the samples was $1.8-2.0 \mathrm{U} \mathrm{mL}^{-1}$ which corresponds to a 100 -fold dilution of the initial cell free extract in the corresponding $\mathrm{pH}$ value. The study was performed at $25^{\circ} \mathrm{C}$ and mild agitated (60 - 70 rpm) with a J.P Selecta Movil-Rod shaker (Barcelona, Spain). Samples were taken periodically and measured using the activity test explained above.

\section{Immobilization of ADHaa onto Methacrylate/Styrene resins}

In order to characterize the enzyme-carrier interaction, as a first stage, the supports are loaded with low amounts of enzyme so that diffusional limitations are minimized. In this sense, the carriers were loaded with $12-13 \mathrm{U} \mathrm{g}^{-1}$ of support, which equals to $0.9-$ $1.0 \mathrm{mg}$ of enzyme $\mathrm{g}^{-1}$ of support. The immobilization vessel always contained $10 \%$ $(\mathrm{w} / \mathrm{v})$ of the carrier and the immobilization always proceeded at $25^{\circ} \mathrm{C}$ and mild agitation $(60-$

$70 \mathrm{rpm})$. The activity of the suspension and the supernatant were measured over time. Moreover, the activity of a blank (no support) was also analyzed over time. Once the activity of the suspension and the supernatant were stabilized, the immobilization yield (IY) and retained activity (RA) were calculated as explained elsewhere[36]. All the immobilization procedures described above were also applied to the agarose supports.

The methacrylate/styrene supports presented a broad variety of features which are specified in the Supporting information, Table S1. The immobilization is carried out in a different way depending on the support's characteristics and always according to the supplier's indications. The epoxy functionalized methacrylates (ECR8204F, ECR8215F and ECR8285) were tested using $1 \mathrm{M}$ potassium phosphate (KPi) buffer $\mathrm{pH} 8$ to increase the ionic strength and favor the attachment.

The amino functionalized carriers (ECR8309F, ECR8315F, ECR8409F and 8415F) were studied using $50 \mathrm{mM} \mathrm{KPi}$ buffer $\mathrm{pH}$ 7. The immobilization with amino functionalized supports is divided in three steps: i) ionic adsorption of the enzyme onto the

support (0.5h) ii) addition of $10 \mathrm{mM} \mathrm{N}$-(3-dimethylaminopropyl)- N'-ethylcarbodiimide (EDC) and incubation for 1.5 hours to promote the covalent binding and iii) addition of $0.5 \mathrm{M} \mathrm{NaCl}$ to desorb all the protein attached non-covalently (0.5h). The nonfunctionalized supports (ECR8806F, ECR1061M and ECR1030M) were tested using $50 \mathrm{mM} \mathrm{KPi} \mathrm{pH} \mathrm{7.} \mathrm{Finally,} \mathrm{the} \mathrm{amino} \mathrm{resins} \mathrm{were} \mathrm{further} \mathrm{functionalized} \mathrm{with} 2 \%$ (w/v) glutaraldehyde for $60 \mathrm{~min}$ at $25^{\circ} \mathrm{C}$ leaving free aldehyde groups on the surface of the carrier. The immobilization was carried out using $50 \mathrm{mM}$ KPi buffer $\mathrm{pH} 7$. The criteria wether a support is a good candidate for further optimization was defined as $40 \%$ immobilization yield and $20 \%$ retained activity.

Immobilization of ADHaa onto Mana- agarose and Epoxyagarose

The first stage of the immobilization onto amino-functionalized supports (Manaagarose), the ionic adsorption, was studied in this case. No carbodiimide was added and so, no covalent bond was formed. The support was loaded with $12-13 \mathrm{U} \mathrm{g}^{-1}$ of support 
(0.9 - 1.0 mg of enzyme $\mathrm{g}^{-1}$ of support) and, three different $\mathrm{pH}$ vàlues were tested: 6.0 , 6.5 and $7.0(\mathrm{NaPi}, 50 \mathrm{mM})$.

In the case of Epoxy-agaroses (M1 and M2), the same amount of enzyme used so far, was also loaded here. For the M1, two pH values were tested: 8 and 9 (KPi, 1M). For the epoxy-agarose $\mathrm{M} 2 \mathrm{pH} 9(\mathrm{KPi}, 1 \mathrm{M})$ was tested. At the end of each immobilization (4h)

the mixture was incubated with $0.2 \mathrm{M} \beta$-mercaptoethanol for $2 \mathrm{~h}$ at $25^{\circ} \mathrm{C}$.

Immobilization using high loads of enzyme with epoxy-agaroses M1 and M2 was carried out by loading $476.6 \mathrm{U} \mathrm{g}^{-1}$ of support (36.4mg enzyme $\mathrm{g}^{-1}$ of support). Due to the impossibility of measuring the actual suspension activity, most probably due to the presence of diffusional limitations, the final specific activity was calculated assuming that the retained activity (\%) is maintained from the characterization study[44].

In order to calculate the theoretical final specific activity of the immobilized derivate (U $\mathrm{g}^{-1}$ support) the procedure explained below these lines was followed. First, the Attached units were calculated from the measured supernatant activity and the initial loaded activity. The Attached units (theoretical units attached to the support) equal to the units of activity missing from the supernatant (Equation 1):

Attached units $\left(U g^{-1}\right)=$ Activity loaded $\left(U m L^{-1}\right)-$ Activity supernatant $\left(U m L^{-1}\right)$ xTotal volume $(\mathrm{mL})$ Support loaded $(g)$

Then, the Multiplying factor was calculated with the RA and IY values obtained in the characterization stage. The Multiplying factor results from dividing the retained activity by the immobilization yield at each given time. Finally, the Specific activity was obtained. It is the final theoretical specific activity ( $\mathrm{Ug}^{-1}$ support) of the immobilized derivate. It is the product of multiplying the Attached units by the Multiplying factor.

Reaction set up and conditions

The reactions were performed in a $20 \mathrm{~mL}$ syringe-like reactor (MultiSynTech $\mathrm{GmbH}$, Witten, Germany) with a porous plate disposed at the bottom that served as oxygen diffuser and as a filter for the immobilized derivates. The syringe was submerged in a thermostated vessel $\left(30^{\circ} \mathrm{C}\right)$ and it was stirred $(1000 \mathrm{rpm})$ either magnetically or mechanically with a stainless steel stirrer.

The conditions for both soluble and immobilized reactions were: $10 \mathrm{~mL}$ total volume, $50 \mathrm{mM}$ NaPi buffer $\mathrm{pH}$ 7.2, $50 \mathrm{mM}$ 4-hydroxyisophorone, $1 \mathrm{mM}$ NADP+ and $0.45 \mathrm{~mL}$ min-1 $\mathrm{O}_{2}$ flow regulated with a mass-flow controller F-200CV-005-AAD-11V(Bronkhorst HI-TEC BV, Ruurlo, The Netherlands).

The soluble reaction contained 5\% (v/v) of ADHaa lysate (271.6 $\mathrm{U} \mathrm{mL}^{-1}$ of CFE) and $3 \%(\mathrm{v} / \mathrm{v})$ of NOX lysate (2032.2 $\mathrm{U} \mathrm{mL}^{-1}$ of CFE) while the reactions with immobilized ADHaa contained 10\% (w/v) of ADHaa immobilized derivate (106.4 or $132 \mathrm{U} \mathrm{g}^{-1}$ of support) and 3\% (v/v) of NOX lysate (2032.2 U mL-1 of CFE). In the second case, at the end of each cycle of reaction, the reactor content was filtered and the support was washed gently with NaPi buffer $50 \mathrm{mM}$ pH 7.2.

Substrate and product analysis by HPLC-UV

Samples $(50 \mu \mathrm{L})$ were taken periodically to follow the reaction performance and were 10 -fold diluted in buffer NaPi $50 \mathrm{mM} \mathrm{pH} 7.2$ and then 40 -fold diluted in acetonitrile. 
After centrifuging and filtering (pore size $\varnothing 0.45 \mu \mathrm{m}$ ) the samples were analyzed by a high performance liquid chromatograph HPLC Dionex UltiMate 3000 equipped with a Variable Wavelength detector (Thermo Fisher, Massachusetts, USA) and a reversephase column CORTCS C18+ 2.7 $\mu \mathrm{m} 4.6 \times 150 \mathrm{~mm}$ from Waters (Massachusetts,USA). To perform the analysis, $15 \mu \mathrm{L}$ of sample were injected in a $0.7 \mathrm{~mL} \mathrm{~min}^{-1}$ mobile phase flow and the column was kept at $40^{\circ} \mathrm{C}$. The solvents consisted on: A) $0.1 \%$ trifluoroacetic acid in $\mathrm{H}_{2} \mathrm{O}$ miliQ and B) $0.095 \%$ trifluoroacetic acid in acetonitrile/ $\mathrm{H}_{2} \mathrm{O}$ milliQ 4:1 (v/v). Samples were eluted using a gradient of solvents: $95 \%$ of A (5\% of B) at the beginning, to $35 \%$ of $\mathrm{A}(65 \%$ of $\mathrm{B})$ at $0.5 \mathrm{~min}$ and down to $5 \%$ of $\mathrm{A}(95 \%$ of $\mathrm{B})$ at $8 \mathrm{~min}$; then back to $95 \%$ of $\mathrm{A}(5 \%$ of B) at $8.1 \mathrm{~min}$ and hold it as such until $13 \mathrm{~min}$.

Two chromatograms corresponding to Figure $4 \mathrm{~B}$ experiment (0h and $24 \mathrm{~h}$ samples) are presented in Supporting information, Figure S2.

\section{Acknowledgements}

The research for this work has received funding from the European Union project ROBOX (grant agreement $n^{\circ}$ 635734) under EU’s Horizon 2020 Programme Research and Innovation actions H2020-LEIT BIO-2014-1. This document reflects only the author's view and the Agency is not responsible for any use that may be made of the information it contains. The Department of Chemical, Biological and Environmental Engineering of Universitat Autònoma de Barcelona constitutes the Biochemical Engineering Unit of the Reference Network in Biotechnology and the research group 2017 SGR 1462, Generalitat de Catalunya. Authors also thank COST Action CM 1303Systems Biocatalysis for financial support. Jordi Solé acknowledges also UAB for funding his Ph.D. grant and Miquel García Bofill for his kind help with the graphical abstract.

Keywords: alcohol dehydrogenase, biocatalysis, immobilization, keto-isophorone and recycling.

\section{References}

[1] J. C. Serrano-Ruiz, R. Luque, A. Sepúlveda-Escribano, Chem. Soc. Rev. 2011, 40, 5266.

[2] L. A. Lucia, BioResources 2008, 3 (4), 981-982.

[3] A. Arevalo-Gallegos, Z. Ahmad, M. Asgher, R. Parra-Saldivar, H. M. N. Iqbal, Int. J. Biol. Macromol. 2017, 99,308-318.

[4] F. H. Isikgor, C. R. Becer, Polym. Chem. 2015, 6, 4497-4559.

[5] F. Zia, K. M. Zia, M. Zuber, S. Kamal, N. Aslam, Carbohydr. Polym. 2015, 134, 784-798.

[6] J. Mao, X. Hu, H. Li, Y. Sun, C. Wang, Z. Chen, Green Chem. 2008, 10, 827.

[7] S. Paganelli, F. Battois, M. Marchetti, R. Lazzaroni, R. Settambolo, S. Rocchiccioli, J. Mol. Catal. A Chem. 2006, 246, 195-199.[a]

[8] W. Bonrath, T. Netscher, Appl. Catal. A Gen. 2005, 280, 55-73.

[9] C. Beck, T. Mallat, A. Baiker, J. Catal. 2000, 195, 79-87.

[10] E. F. Murphy, A. Baiker, J. Mol. Catal. A Chem. 2002, 179, 233-241.

[11] C. Wang, G. Wang, J. Mao, Z. Yao, H. Li, Catal. Commun. 2010, 11, 758-762.

[12] W. Zhong, L. Mao, Q. Xu, Z. Fu, G. Zou, Y. Li, D. Yin, H. Luo, S. R. Kirk, Appl. Catal. A Gen. 2014, 486, 193-200. 
[13] Autocondensation of Acetone, 1965, U.S. Patent 3,497,558A.

[14] O. Isler, P. Zeller, Vitam. Horm. 1957, 15, 31-71.

[15] M. Eggersdorfer, D. Laudert, U. Létinois, T. McClymont, J. Medlock, T. Netscher, W. Bonrath, Angew. Chemie Int. Ed. 2012, 51, 12960-12990.

[16] M. Tavanti, F. Parmeggiani, J. R. G. Castellanos, A. Mattevi, N. J. Turner, ChemCatChem 2017, 9, 3338-3348.

[17] S. Dezvarei, J. H. Z. Lee, S. G. Bell, Enzyme Microb. Technol. 2018, 111, 29-37.

[18] C. Aranda, M. Municoy, V. Guallar, J. Kiebist, K. Scheibner, R. Ullrich, J. C. Del

Río, M. Hofrichter, A. T. Martínez, A. Gutiérrez, Catal. Sci. Technol. 2019, 9, 13981405.

[19] I. Kaluzna, A. De Vries, D. Mink, Chim. Oggi-ChemistryToday 2015, 33, 54-57.

[20] I. Kaluzna, T. Schmitges, H. Straatman, D. Van Tegelen, M. Müller, M. Schürmann, D. Mink, Org. Process Res. Dev.2016, 20, 814-819.

[21] M. A. F. Delgove, D. Valencia, J. Solé, K. V Bernaerts, S.M. A. De Wildeman, M. Guillén, G. Álvaro, Appl. Catal. A, Gen. 2019, 572, 134-141.

[22] J. C. S. D. Santos, O. Barbosa, C. Ortiz, A. Berenguer-Murcia, R. C. Rodrigues, R. Fernandez-Lafuente, ChemCatChem 2015, 7, 2413-2432.

[23] R. A. Sheldon, S. van Pelt, Chem. Soc. Rev. 2013, 42, 6223-6235.

24] S. Soni, J. D. Desai, S. Devi, J. Appl. Polym. Sci. 2001, 82, 1299-1305.

[25] M. Uygun, J. Chromatogr. B Anal. Technol. Biomed. Life Sci. 2014, 959, 42-48.

[26] S. B. Jadhav, S. B. Bankar, T. Granström, H. Ojamo, R. S. Singhal, S. A. Survase, Appl. Microbiol. Biotechnol. 2014, 98, 6307-6316.

[27] M. F. Alam, A. A. Laskar, M. Zubair, U. Baig, H. Younus, J.Mol. Catal. B Enzym. 2015, 119, 78-84.

[28] J. Brummund, T. Sonke, M. Müller, Org. Process Res. Dev. 2015, 19, 1590-1595.

[29] B. Petschacher, N. Staunig, M. Müller, M. Schürmann, D. Mink, S. De Wildeman, K. Gruber, A. Glieder, Comput. Struct. Biotechnol. J. 2014, 9, DOI10.5936/csbj.201402005.

[30] G. Rehn, A. T. Pedersen, J. M. Woodley, J. Mol. Catal. B Enzym. 2016, 134, 331339.

[31] C. Mateo, J. M. Palomo, M. Fuentes, L. Betancor, V. Grazu,F. Lopez-Gallego, B. C. C. Pessela, A. Hidalgo, G. Fernendez-Lorente, R. Fernandez-Lafuente, et al., Enzyme Microb. Technol. 2006, 39, 274-280.

[32] P. Zucca, R. Fernandez-Lafuente, E. Sanjust, Molecules 2016, 21, 1-25.

[33] E. Katchalski-Katzir, D. M. Kraemer, J. Mol. Catal. - B Enzym. 2000, 10, 157176.

[34] R. Fernandez-Lafuente, C. M. Rosell, V. Rodriguez, C. Santana, G. Soler, A. Bastida, J. M. Guisán, Enzyme Microb. Technol. 1993, 15, 546-550.

[35] G. Alvaro, R. Fernandez-Lafuente, R. M. Blanco, J. M. Guisán, Appl. Biochem. Biotechnol. 1990, 26, 181-195.

[36] J. Solé, G. Caminal, M. Schürmann, M. Guillén, G. Alvaro, J. Chem. Technol. Biotechnol. 2018, 94, 244-255.

[37] R. A. Sheldon, J. M. Woodley, Chem. Rev. 2018, 118, 801-838.

[38] T. Li, J. P. N. Rosazza, Appl. Environ. Microbiol. 2000, 66, 684-687.

[39] I. Axarli, A. Prigipaki, N. E. Labrou, Biomol. Eng. 2005, 22, 81-88.

[40] L. Sundberg, J. Porath, J. Chromatogr. A 1974, 90, 87-98.

[41] N. G. Munishwar, Methods for Affinity Based Separations for Enzymes and Proteins, Birkhäuser, 2002.

[42] M. M. Bradford, Anal. Biochem. 1976, 72, 248-254.

[43] U. K. Laemmli, Nature 1970, 227, 680-685. 
[44] D. Valencia, M. Guillén, J. L. J. Fürst, J. López-santín, G. Álvaro, J. Chem. Technol. Biotechnol. 2017, 93, 985-993

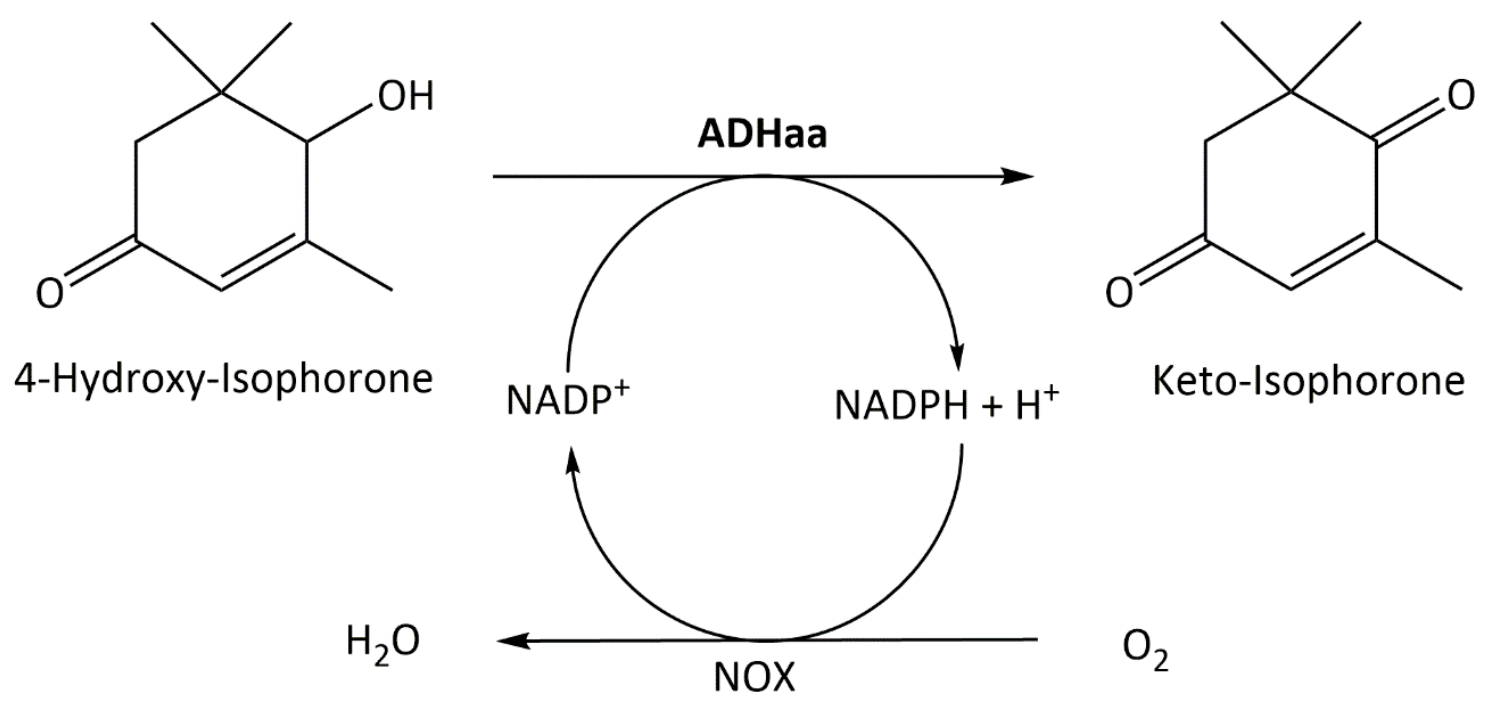

Figure 1 


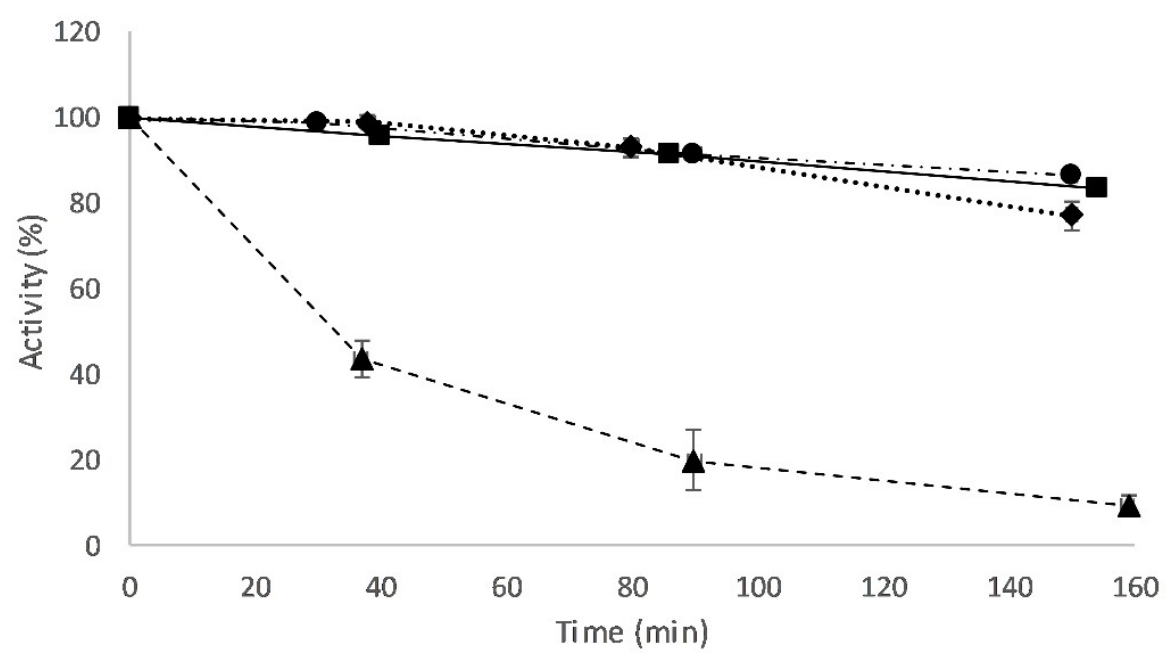

Figure 2

A

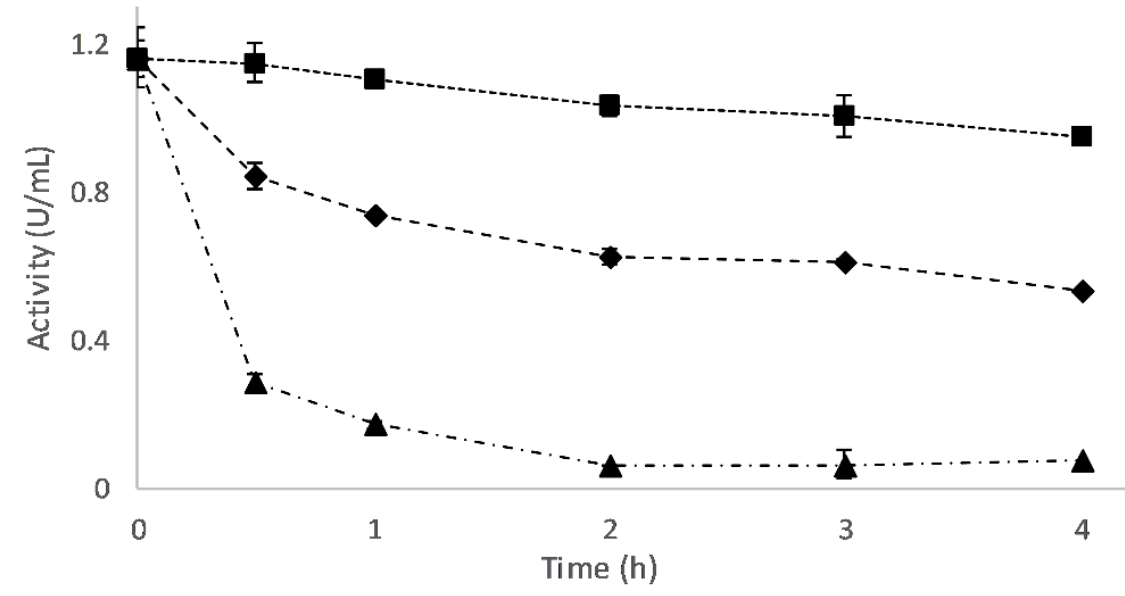




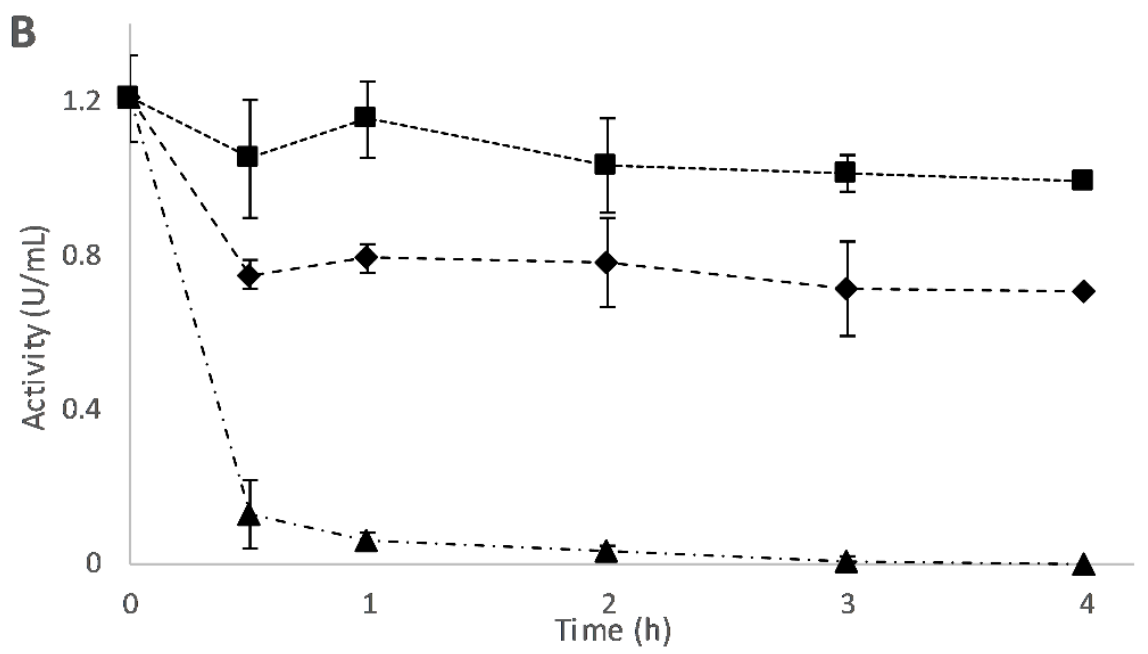

Figure 3 

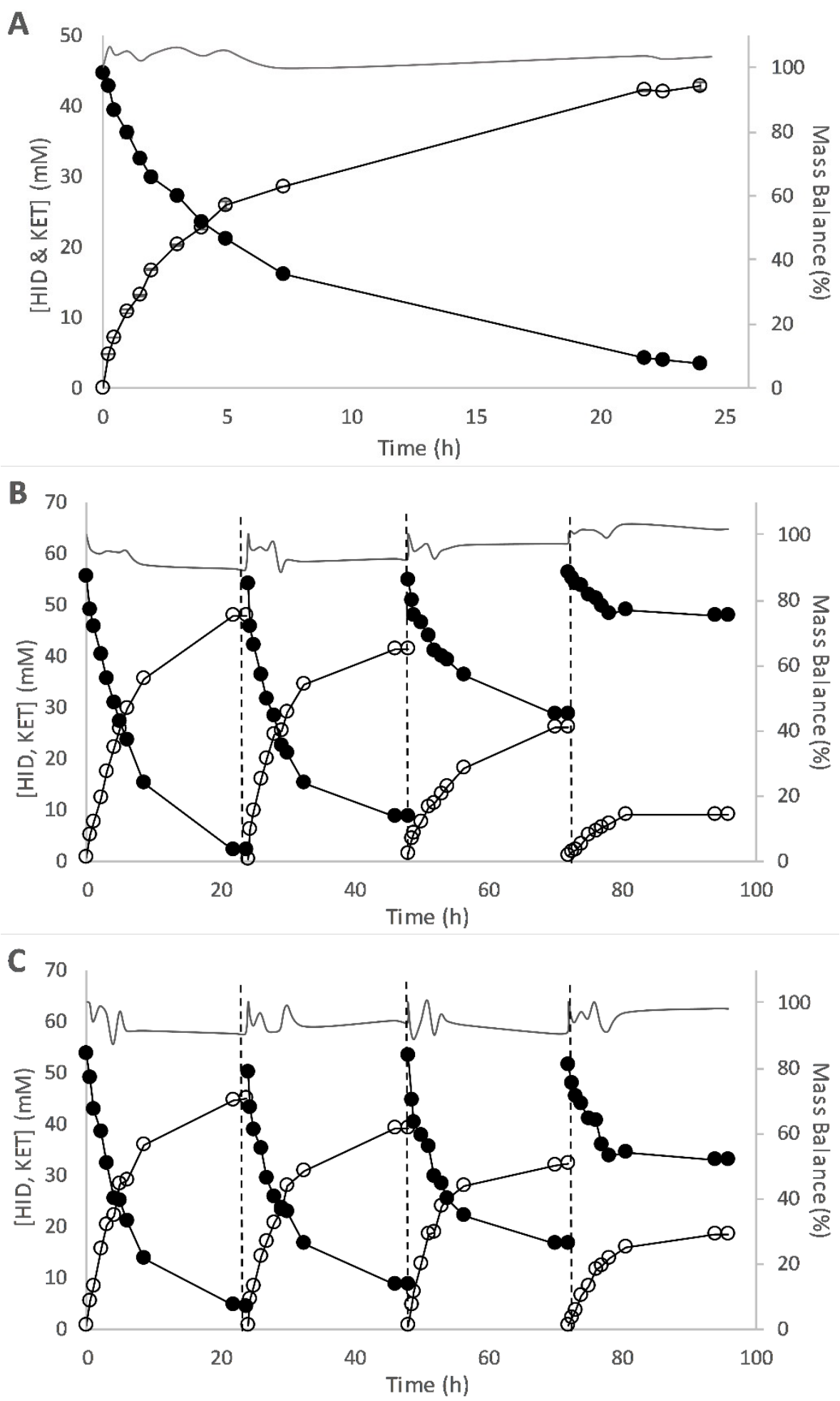

Figure 4. 
Figure Captions:

Figure 1. Biocatalyzed oxidation of 4-hydroxy-isophorone (HID) to keto-isophorone (KET) with a two-enzyme system using an alcohol dehydrogenase (ADHaa) and NADPH oxidase (NOX) to regenerate the NADPH using oxygen as a sacrificial substrate.

Figure 2. ADHaa relative activity over time measured at different $\mathrm{pH}$ values (of KPi buffers): pH 6 (black triangles and discontinuous line), pH 7 (black squares and continuous line), pH 8 (black rhombus and dotted line) and pH 9 (black circles and combined discontinuous spot-line-spot). The initial activity of the samples was 1.8 - $2 \mathrm{U}$ $\mathrm{mL}-1 ; 100$-fold dilution of the initial lysate. Samples were maintained at $25^{\circ} \mathrm{C}$ and mild agitation. The error bars correspond to the standard error calculated from at least two replicates.

Figure 3. Immobilization course of ADHaa onto: A) Epoxy-agarose-M1 and B) Epoxyagarose-M2. The experiments were performed loading the supports with low amounts of enzyme (12 U g-1 support). The immobilization was carried out using $1 \mathrm{M}$ KPi buffer $\mathrm{pH}$ 9. Samples were maintained at $25^{\circ} \mathrm{C}$ and mild agitation. The graph shows the activity of the blank (black squares), the supernatant (black triangles) and the suspension

(black rhombus) over time. The error bars correspond to standard error of at least two replicates.

Figure 4. Oxidation of 4-hydroxy-isophorone to keto-isophorone on $10 \mathrm{~mL}$ reactor with ADHaa and NOX as the cofactor regeneration enzyme. The graphs show the reaction course of KET (white spots), HID (black spots) and mass balance (continuous grey line with no spots). A) Reaction using the enzymes on its soluble form: 5\% (v/v)of ADHaa lysate (180.9 $\mathrm{U} \mathrm{mL}^{-1}$ of CFE) and 3\% (v/v) of NOX lysate (2032.2 $\mathrm{U} \mathrm{mL}^{-1}$ of CFE); B) Reaction cycles with magnetic stirring and immobilized ADHaa and soluble NOX lysate: $10 \%(\mathrm{w} / \mathrm{v})$ of ADHaa immobilized derivate (106.4 U g-1 of support) and 3\% $(\mathrm{v} / \mathrm{v})$ of NOX lysate (2032.2 U mL-1 of CFE) and C) Reaction cycles with mechanical stirring and immobilized ADHaa and soluble NOX lysate: 10\% (w/v) of ADHaa immobilized derivate (131.6 $\mathrm{U} \mathrm{g}^{-1}$ of support) and 3\% (v/v) of NOX lysate (2032.2 U $\mathrm{mL}^{-1}$ of CFE). Conditions: temperature $30^{\circ} \mathrm{C}$; stirring rate $1000 \mathrm{rpm}$; oxygen flow 0.45 $\mathrm{mL} \mathrm{min}^{-1}$; $\mathrm{pH}$ 7.2; [HID] $50 \mathrm{mM}$ and [NADP+] $1 \mathrm{mM}$. 
Table 1. Characterization of the E. coli cell free extracts overexpressing the ADHaa and NOX. The standard error

$( \pm \%)$ was calculated from at least two replicates.

\begin{tabular}{cccc}
\hline Enzyme & [Protein] $\left(\mathrm{mg} \mathrm{mL}^{-1}\right)$ & Enzyme content (\%) & Specific activity (U $\left.\mathbf{~ m g}^{-1} \mathbf{~ e n z}\right)$ \\
\hline ADHaa & $34.8 \pm 2.1$ & $39.6 \pm 1.2$ & $13.1 \pm 0.6$ \\
\hline NOX & $50.1 \pm 2.3$ & $61.0 \pm 1.2$ & $66.5 \pm 0.8$ \\
\hline
\end{tabular}

Table 2. Results regarding the immobilization of ADHaa onto Methacrylate/Styrene (Purolite ${ }^{\circledR}$ ) resins and description of the support's features. The experiments were performed loading the support with low amounts of enzyme (12 $\mathrm{U} \mathrm{g}^{-1}$ support) in order to characterize the enzyme-support interaction behaviour. Only those experiments with at least $90 \%$ immobilization yield and $20 \%$ retained activity are presented. Further information regarding other supports screened can be found in Supporting information,

\begin{tabular}{cccccccc}
\hline Code & $\begin{array}{c}\text { Functional } \\
\text { group } \\
\text { (Linker) }\end{array}$ & Matrix & Interaction & $\begin{array}{c}\text { Pore } \\
\text { diameter } \\
(\AA)\end{array}$ & $\begin{array}{c}\text { Particle } \\
\text { size }(\mu \mathrm{m})\end{array}$ & $\begin{array}{c}\text { Immobiliza } \\
\text { tion yield } \\
(\%)\end{array}$ & $\begin{array}{c}\text { Retained } \\
\text { acitivty } \\
(\%)\end{array}$ \\
\hline ECR8215F & Epoxy & Methacrylate & Covalent & $\begin{array}{c}1200- \\
1800\end{array}$ & $150-300$ & $99.9 \pm 0.1$ & $23.1 \pm 1.9$ \\
\hline ECR8409F & Amino (C6) & Methacrylate & lonic/Covalent & $600-1200$ & $150-300$ & $99.3 \pm 0.1$ & $20.2 \pm 2.1$ \\
\hline
\end{tabular}

Table 3. Immobilization of ADHaa onto Mana-agarose and Epoxy-agarose-M1 and M2. The experiments were performed loading the support with low amounts of enzyme (12 $\mathrm{U} \mathrm{g}^{-1}$ support). The standard error ( $\pm \%$ ) was calculated from at least two replicates.

\begin{tabular}{|c|c|c|c|c|c|c|}
\hline Support & $\begin{array}{l}\text { Activation grade } \\
\text { ( } \mu \mathrm{mol} \mathrm{g}^{-1} \text { support) }\end{array}$ & $\begin{array}{c}\text { Kind of } \\
\text { interaction }\end{array}$ & $\mathrm{pH}$ & $\begin{array}{l}{[\mathrm{KPi}]} \\
(\mathrm{M})\end{array}$ & $\begin{array}{l}\text { Immobilization } \\
\text { Yield (\%) }\end{array}$ & $\begin{array}{c}\text { Retained } \\
\text { Activity (\%) }\end{array}$ \\
\hline \multirow{3}{*}{$\begin{array}{l}\text { Mana- } \\
\text { agarose }\end{array}$} & \multirow{3}{*}{$40-60$} & \multirow{3}{*}{ Ionic } & 6 & \multirow{3}{*}{0.05} & $88.2 \pm 0.7$ & $13.7 \pm 2.3$ \\
\hline & & & 6.5 & & $76.1 \pm 2.3$ & $4.8 \pm 1.0$ \\
\hline & & & 7 & & $14.3 \pm 3.3$ & $4.7 \pm 1.2$ \\
\hline \multirow{2}{*}{$\begin{array}{c}\text { Epoxy- } \\
\text { agarose-M1 }\end{array}$} & \multirow{2}{*}{$30 \pm 3$} & \multirow{2}{*}{ Covalent } & 8 & \multirow{3}{*}{1} & $40.6 \pm 4.8$ & $33.9 \pm 3.7$ \\
\hline & & & 9 & & $93.2 \pm 2.4$ & $36.6 \pm 2.5$ \\
\hline $\begin{array}{c}\text { Epoxy- } \\
\text { agarose-M2 }\end{array}$ & $106 \pm 1$ & Covalent & 9 & & $100 \pm 0.0$ & $58.2 \pm 3.5$ \\
\hline
\end{tabular}


Table 4. Immobilization of ADHaa onto Epoxy-agarose-M1 and M2 using maximum loads of enzyme per gram of support. In both cases the offered activity was $476.6 \mathrm{U} \mathrm{g}^{-1}$ of support (36.4 $\mathrm{mg}$ enzyme $\mathrm{g}^{-1}$ of support). The immobilization was carried out using 1 $\mathrm{M}$ KPi buffer $\mathrm{pH}$ 9. Samples were maintained at $25^{\circ} \mathrm{C}$ and mild agitation.

\begin{tabular}{c|ccc|ccc}
\hline & \multicolumn{3}{|c|}{ Epoxy-agarose-M1 } & \multicolumn{3}{c}{ Epoxy-agarose-M2 } \\
\hline $\begin{array}{c}\text { Time } \\
\text { (h) }\end{array}$ & $\begin{array}{c}\text { Attached } \\
\text { units }\left(\mathrm{U} \mathrm{g}^{-1}\right. \\
\text { support) }\end{array}$ & $\begin{array}{c}\text { Multiplying } \\
\text { factor } \\
\text { (RA/IY) }\end{array}$ & $\begin{array}{c}\text { Specific } \\
\text { activity }\left(\mathrm{U} \mathrm{g}^{-1}\right. \\
\text { support) }\end{array}$ & $\begin{array}{c}\text { Attached } \\
\text { units }\left(\mathrm{U} \mathrm{g}^{-1}\right. \\
\text { support) }\end{array}$ & $\begin{array}{c}\text { Multiplying } \\
\text { factor } \\
\text { (RA/IY) }\end{array}$ & $\begin{array}{c}\text { Specific } \\
\text { activity }\left(\mathrm{U} \mathrm{g}^{-1}\right. \\
\text { support) }\end{array}$ \\
\hline $\mathbf{1}$ & 189.2 & 0.57 & 108.4 & 222.8 & 0.64 & 142.0 \\
\hline $\mathbf{2}$ & 207.8 & 0.51 & 106.4 & 266.5 & 0.64 & 169.5 \\
\hline $\mathbf{3}$ & 236.9 & 0.51 & 119.9 & 301.0 & 0.59 & 177.4 \\
\hline $\mathbf{4}$ & 261.9 & 0.42 & 109.9 & 336.4 & 0.58 & 195.7 \\
\hline
\end{tabular}

Table 5. Final summary of the performed reactions, Figure 4 A, B and C. The conditions are the same as the ones reported before for those figures.

\begin{tabular}{|c|c|c|c|c|c|c|c|c|}
\hline Figure & Enzyme & Immob & Soluble & $\begin{array}{l}\text { Activity in the } \\
\text { reactor }\left(\mathrm{U} \mathrm{mL}^{-1}\right)\end{array}$ & $\begin{array}{l}\text { Enzyme loaded in } \\
\text { the reactor }(\mathrm{mg})\end{array}$ & $\begin{array}{l}\text { Total KET formed } \\
(\mathrm{mg})\end{array}$ & $\begin{array}{l}\text { Biocatalyst yield (g } \\
\text { KET g }{ }^{-1} \text { enzyme) }\end{array}$ & $\begin{array}{l}\text { Improveme } \\
\text { nt factor }\end{array}$ \\
\hline \multirow{2}{*}{ Figure $4 \mathrm{~A}$ ) } & ADHaa & & $x$ & 9.1 & 6.9 & \multirow{2}{*}{65.2} & 9.5 & - \\
\hline & NOX & & $x$ & 61.0 & 9.2 & & 7.1 & - \\
\hline \multirow{2}{*}{ Figure $4 \mathrm{~B}$ ) } & ADHaa & $\mathrm{x}$ & & 10.6 & 8.1 & \multirow{2}{*}{189.1} & 23.4 & 2.5 \\
\hline & NOX & & $x$ & $61.0 \times 4$ & $9.2 \times 4$ & & 5.1 & 0.7 \\
\hline \multirow{2}{*}{ Figure $4 \mathrm{C}$ ) } & ADHaa & $x$ & & 13.2 & 10.1 & \multirow{2}{*}{204.5} & 20.2 & 2.1 \\
\hline & NOX & & $x$ & $61.0 \times 4$ & $9.2 \times 4$ & & 5.6 & 0.8 \\
\hline
\end{tabular}

